\title{
Physical activity and environmental enrichment regulate the generation of neural precursors in the adult mouse substantia nigra in a dopamine-dependent manner
}

\author{
Philipp Klaissle, Anne Lesemann', Petra Huehnchen ${ }^{1}$, Andreas Hermann², Alexander Storch 2,3,4 \\ and Barbara Steiner ${ }^{1 *}$
}

\begin{abstract}
Background: Parkinson's disease is characterized by a continuous loss of neurons within the substantia nigra (SN) leading to a depletion of dopamine. Within the adult SN as a non-neurogenic region, cells with mainly oligodendrocytic precursor characteristics, expressing the neuro-glial antigen-2 (NG2) are continuously generated. Proliferation of these cells is altered in animal models of Parkinson's disease (PD). Exercise and environmental enrichment re-increase proliferation of $\mathrm{NG}^{+}$cells in PD models, however, a possible mechanistic role of dopamine for this increase is not completely understood. $\mathrm{NG}^{+}$cells can differentiate into oligodendrocytes but also into microglia and neurons as observed in vitro suggesting a possible hint for endogenous regenerative capacity of the SN. We investigated the role of dopamine in NG2-generation and differentiation in the adult SN stimulated by physical activity and environmental enrichment.
\end{abstract}

Results: We used the 1-methyl-4-phenyl-1,2,3,6-tetrahydropyridine (MPTP)-model for dopamine depletion and analysed newborn cells in the SN at different maturation stages and time points depending on voluntary physical activity, enriched environment and levodopa-treatment. We describe an activity- induced increase of new NG2-positive cells and also mature oligodendrocytes in the SN of healthy mice. Running and enriched environment refused to stimulate NG2-generation and oligodendrogenesis in MPTP-mice, an effect which could be reversed by pharmacological levodopa-induced rescue.

Conclusion: We suggest dopamine being a key regulator for activity-induced generation of NG2-cells and oliogodendrocytes in the SN as a potentially relevant mechanism in endogenous nigral cellular plasticity.

Keywords: Physical activity, Environmental enrichment, Dopamine, NG2, Oligodendrocytes, Substantia nigra

\section{Background}

The hallmark of Parkinson's disease (PD) is the degeneration of dopaminergic neurons in the substantia nigra (SN) [1]. Although the adult brain bears the lifelong capacity to generate neural precursor cells and neurons, regeneration of nigral dopaminergic neurons remains controversially discussed [2-5]. In animal models of PD glial cells with features of oligodendrocytic precursors such as the expression

\footnotetext{
* Correspondence: barbara.steiner@charite.de

'Department of Neurology, Charité University Medicine Berlin; CCM,

Charitéplatz 1, Berlin 10117, Germany

Full list of author information is available at the end of the article
}

of the neuro-glial antigen 2 (NG2) are continuously generated in the adult SN $[5,6]$. Voluntary physical activity and environmental enrichment robustly regulate proliferation of $\mathrm{NG}^{+}$oligodendrocytic precursors in the $\mathrm{SN}$ [6]. We previously showed a decreased nigral $\mathrm{NG}^{+}$cell proliferation following 6-hydroxydopamine (6-OHDA)-induced dopamine depletion in rats. This effect was restored by physical activity and environmental enrichment and correlated with improved motor behavior [6]. If and how these new cells could add to an endogenous restorative pool following neurodegeneration remains unclear. It is known, that lack of dopamine leads to decreased generation of

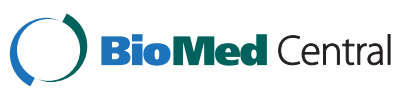


neurons [7-10], however the regulation of $\mathrm{NG}^{+}$cells and oligodendrocytes in PD brain has so far not been described in detail. Few studies investigated orthotopic neural (mainly glial) regeneration in the adult $\mathrm{SN}$, the major origin of dopaminergic pathways, but refused observing neurogenesis $[2,3,5,11,12]$. It is known, that activity induced proliferation, differentiation and survival of glial cells is regulated differentially from neuronal cells [13-15]. Especially maturation of $\mathrm{NG}^{+}$cells is strongly influenced by physical exercise and environmental enrichment but also by pathological processes in various areas of the adult brain [14-18].

We analysed newly generated nigral $\mathrm{NG}^{+}$cells, oligodendrocytes and Nestin- $\mathrm{GFP}^{+}$neural precursors over time, depending on the presence of dopamine and stimulation by physical activity and environmental enrichment. Oligodendrocyte and $\mathrm{NG}^{+}$derived factors have been postulated to play a neurotrophic/neuroprotective role for dopaminergic neurons $[19,20]$. On the other hand, disturbances in nigral oligodendrogenesis seem to be pathognomonic in PD brain [21,22]. As dopamine is involved in activity-induced neuroprotection in PD brain [23-25], we analysed new nigral NG2 ${ }^{+}$ cells and mature oligodendrocytes following 1-methyl-4phenyl-1,2,3,6-tetrahydropyridine (MPTP) lesion at various time points combined with physical activity and enriched environment. To differentiate between the dopamine and activity effect on oligodendrocytic and other neural precursors, we used mice expressing the green fluorescent protein (GFP) under the promoter of the neural precursor marker Nestin and quantified newborn cells by incorporation of the proliferation marker bromodeoxyuridine (BrdU). In vitro analyses were performed to study the differentiation potential of precursor isolated from the $\mathrm{SN}$ following MPTP-treatment. L-dopa treatment was used to rescue a dopamine deficit in MPTP treated mice.

\section{Results}

Increased numbers but reduced survival of new nigral cells following levodopa-treatment of MPTP-mice

To analyse the effects of MPTP-treatment on generation of newborn cells within the SNpc and SNpr, we quantified $\mathrm{BrdU}^{+}$cells at various time points after MPTP treatment. Three days after BrdU administration, we detected an increase in $\mathrm{BrdU}^{+}$cells in the SN of MPTP-treated mice compared to saline-treated controls in both the $\mathrm{SNpc}$ and the SNpr (Figure 1A-C; SNpc: one-wayANOVA: $p<0001 \mathrm{~F}_{(7 ; 31)}$ : 3.4; SNpr: one-way-ANOVA: $p<0.001 \mathrm{~F}_{(7 ; 31)}$ : 30.6). At 10 and 28 days after BrdU, no differences in the numbers of $\mathrm{BrdU}^{+}$cells were detected between MPTP-treated and control groups (Figure 1B, C). Long term observations (70d after BrdU and after MPTP), showed a significant decrease in the numbers of
$\mathrm{BrdU}^{+}$cells in the MPTP-treated mice compared to controls, indicating a reduced long-term survival of newborn nigral cells in the SN (Figure 1B, C).

After 10 days of levodopa treatment, significant effects of MPTP on the numbers of new nigral cells compared to healthy controls were observed (two-way ANOVA $\left.\mathrm{F}_{(1 ; 16)}: 14.6, p=0.002\right)$. The same held true for levodopa treatment compared to saline in MPTP-mice (two-way ANOVA $\mathrm{F}_{(1 ; 16)}$ : 23.4, $p<0.001$; Figure 1D, E). The significant interaction effect (two-way ANOVA $\mathrm{F}_{(1 ; 16)}$ : 8.8, $p=0.009$ ) indicates that healthy controls and parkinsonian mice were affected differently by levodopa, as $\mathrm{BrdU}^{+}$cell numbers increased after levodopa treatment in MPTPmice but not in controls $(p=0.001)$. Levodopa-treated MPTP mice also showed an increase in nigral BrdU ${ }^{+}$ cells compared to MPTP-treated mice without substitution of levodopa $(p=0.001)$.

\section{Generation of nigral NG2 ${ }^{+}$cells is increased in levodopa-treated MPTP-mice}

At all evaluated time points numerous $\mathrm{BrdU}^{+}$cells expressed NG2. In the three- and ten day groups 46$56 \%$ of BrdU-labelled cells of healthy animals were $\mathrm{NG}^{+}$. This percentage decreased over time to $13 \%$ after 70 days (Figure 2A). In the acute phase, 3 days after BrdU-injection MPTP led to an increase in the absolute numbers $\mathrm{NG}^{+} / \mathrm{BrdU}^{+}$cells in the $\mathrm{SN}$ compared to saline-treated controls (one-way ANOVA: $p=0.005$, $\left.\mathrm{F}_{(7 ; 26)}: 8.09\right)$. At all further time points MPTP had no effect on the numbers of newborn $\mathrm{NG}^{+}$cells (Figure $2 \mathrm{~B}, 3 \mathrm{~A}$ ).

We observed a significant interaction effect between levodopa and MPTP on the amount of newly generated $\mathrm{NG}^{+}$cells (2way ANOVA $\mathrm{F}_{(1 ; 13)} 5.6, p=0.034$ ). Specifically levodopa led to an increase of $\mathrm{NG}^{+}$cells in MPTPtreated mice, but not in healthy animals (Figure 3B).

\section{Nigral oligodendrogenesis is disturbed by MPTP but remains unchanged by levodopa-rescue}

NG2 is described as a marker for oligodendrocytic precursor cells (OPCs) with also a potential to differentiate into neurons or other non-neuronal cells in vitro ([19,26-29]. Since a decrease of nigral $\mathrm{BrdU}^{+}$and $\mathrm{NG}^{+}$cells over time was apparent in all groups we hypothesized that this could be due to maturation into oligodendrocytes. Mature oligodendrocytes were characterized by CNPase-expression. Three days after BrdU-administration no $\mathrm{BrdU}^{+} / \mathrm{CNPase}^{+}$ cells were detected in any group (Figure $2 \mathrm{C}, 3 \mathrm{C}$ ). Ten days after BrdU, we found new CNPase ${ }^{+}$oligodendrocytes in the SN of both MPTP- and saline-treated mice without differences in the numbers of these cells between groups (one-way ANOVA: $p=0.83, \mathrm{~F}_{(5 ; 18)}: 11.5$; Figure $3 \mathrm{C}$ ). An increase in the numbers of $\mathrm{BrdU}^{+} / \mathrm{CNPase}^{+}$cells over time between 10 and 28 days was detectable in healthy, salinetreated mice in parallel to the decrease of new NG2- 

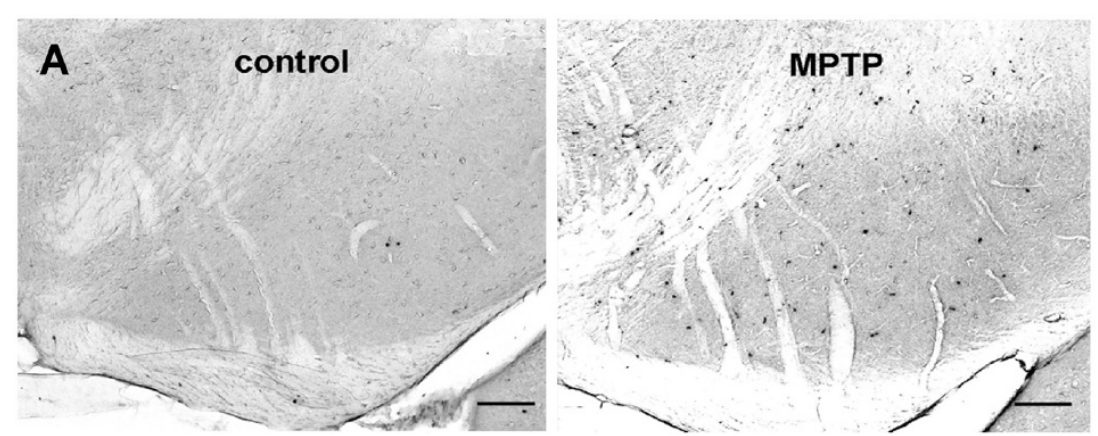

B

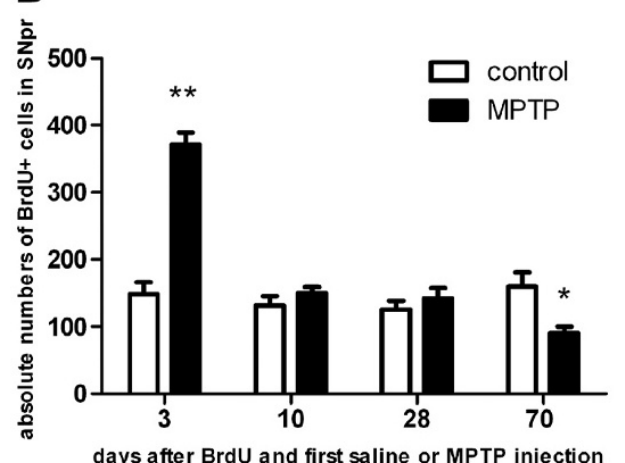

C

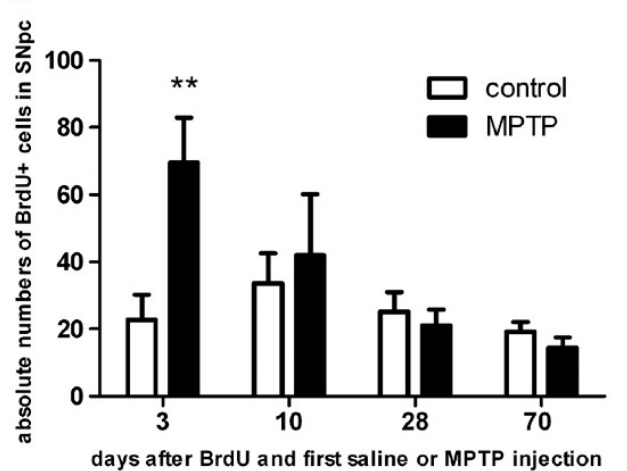

D

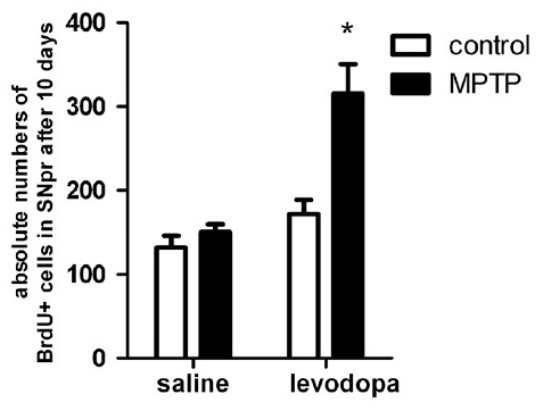

E

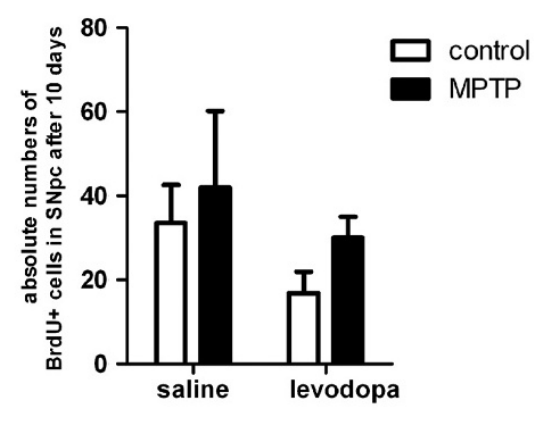

Figure 1 Histological analysis and quantification of the absolute numbers of $\mathrm{BrdU}^{+}$cells in the substantia nigra pars reticulata (SNpr) and compacta (SNpc) at different time points following BrdU and first saline or MPTP injection. Data are expressed as mean +/- S.E.M. A: BrdU-positive cells in the SN of healthy control animals (control) versus MPTP-treated animals (MPTP). Representative coronal 40 $\mathrm{mm}$ sections at

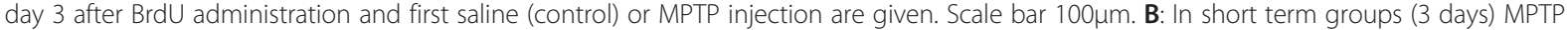
induced a significant increase in the number of $\mathrm{BrdU}^{+}$cells in the SNpr compared to saline-treated controls. In the 70 days-group MPTP caused a significant decrease in the numbers of BrdU+ cells compared to saline-treated controls. ${ }^{*} p<0.05,{ }^{* *} p<0.001$ versus corresponding control ( $n=5$; LSD post hoc test). C: Only in short term groups ( 3 days) MPTP induced a significant increase in the number of BrdU ${ }^{+}$cells compared to saline-treated controls in the SNpc. ${ }^{* *} p<0.001$ versus corresponding control $(n=5)$. D: In the SNpr there was a significant interaction effect between MPTP-treatment (MPTP versus control) and levodopa-treatment (L-Dopa versus saline), as levodopa treatment in addition to MPTP-treatment (MPTP + L-Dopa) increased the number of BrdU ${ }^{+}$cells compared to saline-treated controls (control, saline), MPTP and saline treated mice (MPTP, saline) and levodopa-treated mice. ${ }^{*} p<0.05$ versus other groups ( $n \geq 5$; LSD post hoc test). E: There were no effects of levodopa-treatment or MPTP on the number of BrdU' cells in the SNpc.

positive cells possibly as a sign for oligodendrocytic maturation in the healthy $\mathrm{SN}$ (one-way ANOVA: $p=0.001, \mathrm{~F}_{(5 ; 18)}: 11.5$; Figure $\left.3 \mathrm{C}\right)$. In parallel, the percentage of $\mathrm{CNPase}^{+}$cells among all $\mathrm{BrdU}^{+}$cells in healthy animals increased from $13 \%$ at 10 days to $29 \%$ at 28 days and remained at that level at 70 days (26\%; Figure 2A). In MPTP treated mice however, there was no difference in $\mathrm{BrdU}^{+} / \mathrm{CNPase}^{+}$cells at 10 and 28 days (one-way ANOVA: $p=0.67, \mathrm{~F}_{(5 ; 18)}: 11.5$, Figure $3 \mathrm{C}$ ) and the percentage of $\mathrm{CNPase}^{+}$cells among all $\mathrm{BrdU}^{+}$cells 
A
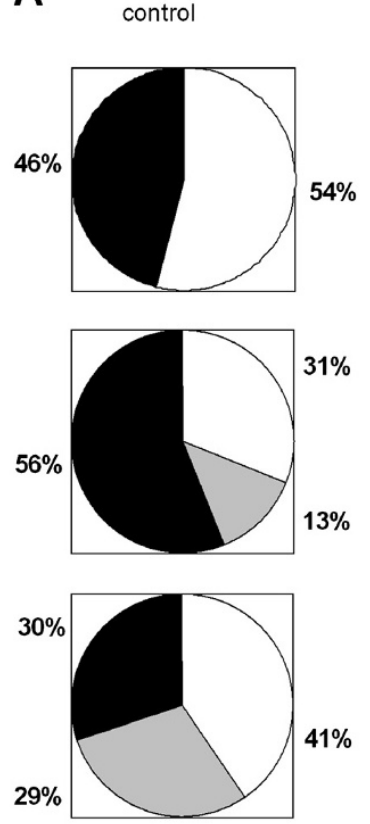

$13 \%$

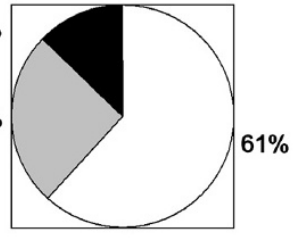

$\square$ BrdU+ $\square$ CNPase+ $\square$ NG2+

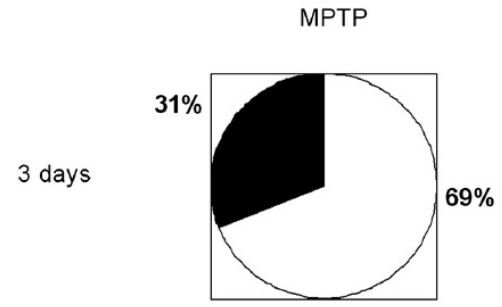

10 days
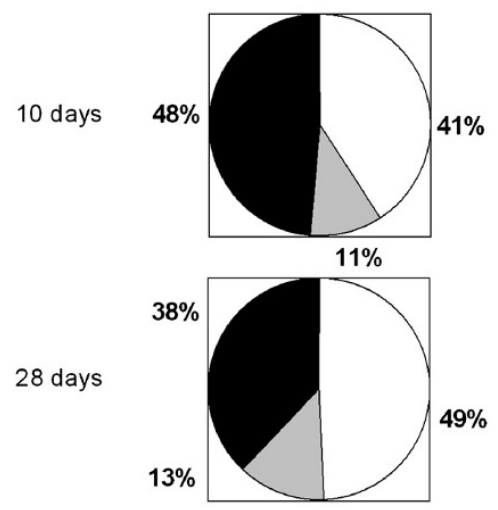

70 days

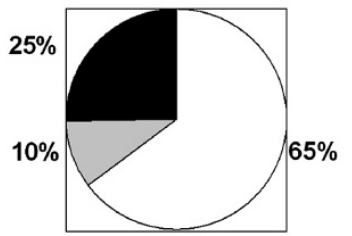

$\square$ BrdU+ $\square$ CNPase+ $\square$ NG2+

B
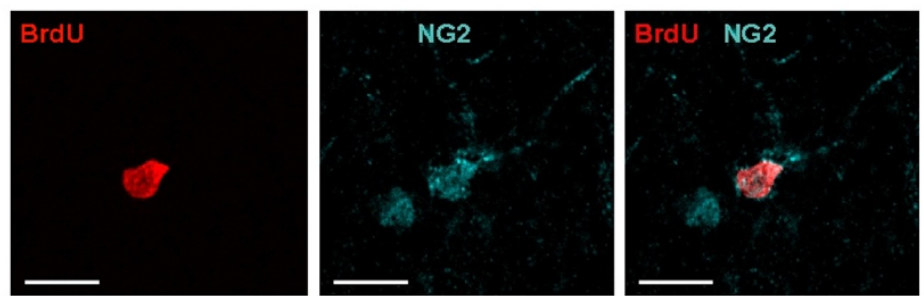

C
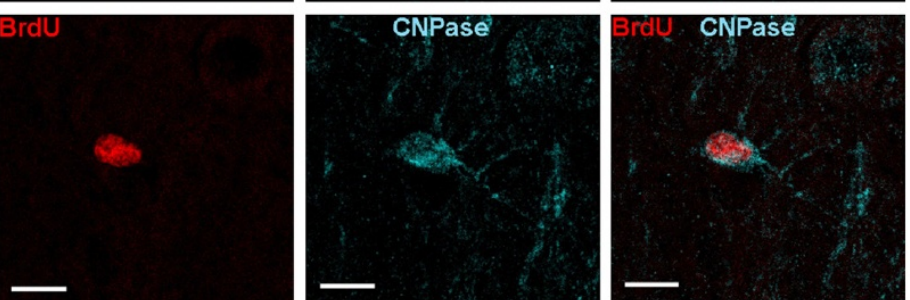

D
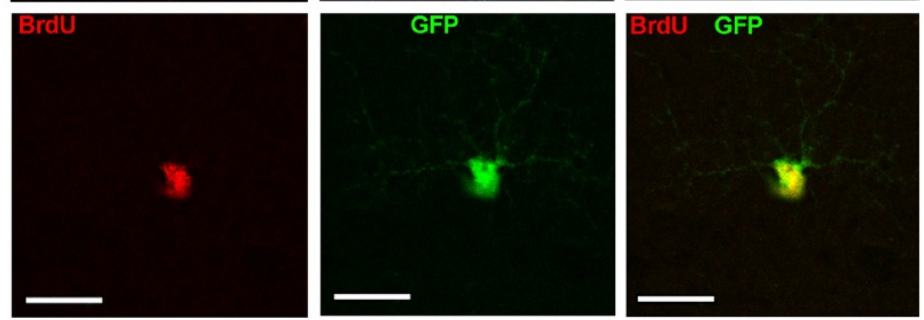

Figure $\mathbf{2}$ (See legend on next page.) 
(See figure on previous page.)

Figure 2 Co-localization of BrdU-positive cells with different cell markers. A: Relative numbers of co-localization of NG2-positive cells with BrdU+ cells (NG2+), CNPase- positive cells with BrdU+ cells (CNPase+) and unidentified BrdU+ cells (BrdU+) in saline treated, healthy controls (left panel) and MPTP treated animals (right panel) at different time points. B-D: Overview of exemplary BrdU+ cells expressing characteristic cell markers in the substantia nigra after 10 days. Left panel shows BrdU (red), central panel shows markers NG2 (blue), CNPase (blue), NesGFP (green), right panel shows overlay. Scale bar $10 \mu \mathrm{m}$.

remained stable ranking between $10-13 \%$ at all later time points (10, 28, 70 days post MPTP, Figure 2A). Moreover, MPTP induced a significant decrease in the number of $\mathrm{BrdU}^{+} / \mathrm{CNPase}^{+}$cells compared to healthy controls after 28 days, with continuous decrease of new $\mathrm{CNPase}^{+}$cells at the 70 days time point (one-way ANOVA: $p<0.001$, $F_{(5 ; 18)}: 11.5$, Figure $\left.3 C\right)$. We could not rescue this effect by treatment with levodopa (Figure 3D).

\section{No influence of dopamine-depletion and levodopa-} treatment on nestin-GFP-expressing neural precursor cells To investigate if the dopaminergic influence also becomes relevant in the stimulation of other neural precursor cell populations in the $\mathrm{SN}$, we quantified Nestin-GFPexpressing cells over time. These cells represent a small population of BrdU+ cells in the $\mathrm{SN}$ with decreasing cell numbers over time from $8.4-11.6 \%$ on the third day to 1.5 $2 \%$ after 70 days (Figure 2D, 3E). In the 3 day groups MPTP induced a significant transient increase in the numbers of Nestin-GFP ${ }^{+}$newborn cells compared to controls as a potential reactive cell response to toxicity. Thus, in the 10 day groups we did not detect any significant differences in numbers of Nestin-GFP ${ }^{+} / \mathrm{BrdU}^{+}$cells, this also held true for 28 and 70 days (Figure 3E). Levodopa treatment did not influence the numbers of new Nestin-GFP ${ }^{+}$cells (two-way $\operatorname{ANOVA~}_{(1 ; 16)} 0.27, p=0.61$, Figure $\left.3 \mathrm{~F}\right)$.

\section{The proliferative effect of physical activity and environmental enrichment on nigral cells is suppressed after MPTP-treatment}

We have previously shown the effects of physical activity (RUN) and environmental enrichment (ENR) on nigral cell proliferation in adult rats [6]. In the present study RUN and ENR increased the numbers of BrdU+ cells in the $\mathrm{SN}$ of healthy mice at all evaluated timepoints (Figure 4A). RUN and ENR had no effect on the numbers of $\mathrm{BrdU}^{+}$cells in the SN of MPTP-treated animals at any time point, suggesting a role for dopamine in activityinduced nigral cell proliferation (one way ANOVA: 3d: $p=0.9, p=0.84,10 \mathrm{~d}: p=0.87, p=0.46,28 \mathrm{~d}: p=0.92, p=0.38$, 70d: $p=0.08, p=0.05, \mathrm{~F}_{(23 ; 80)}: 19.22$, Figure $\left.4 \mathrm{~A}\right)$.

\section{Levodopa rescue re-induces nigral cell generation in MPTP-treated mice}

Assuming a key role for dopamine in activity-induced cell proliferation in the $\mathrm{SN}$, we next tested whether the lack of response to physiological stimulation by RUN and ENR MPTP-treated animals could be reversed by administration of levodopa. MPTP-treated mice received levodopa for 10 consecutive days. In these animals, there was a significant main effect of levodopa treatment (threeway ANOVA $\left.F_{(1 ; 44)} 93.8, p<0.001\right)$ and MPTP-treatment (three-way ANOVA $\mathrm{F}_{(1 ; 4)}$ 12.63, $p=0.001$ ), a significant interaction effect between levodopa-treatment and MPTPtreatment (three-way ANOVA $F_{(1 ; 44)} 72.1, p<0.001$ ) and a significant interaction effect between levodopa, physical stimulation and MPTP (three-way ANOVA $\mathrm{F}_{(2 ; 44)}$ 7.88, $p=0.001$ ) on the numbers of $\mathrm{BrdU}^{+}$cells in the $\mathrm{SN}$ (Figure 4B). Thus, the effects of physiological stimulation on the numbers of $\mathrm{BrdU}^{+}$nigral cells could be restored by levodopa. Administration of levodopa to saline-treated controls had no effect on nigral cell proliferation (two-way ANOVA: $p=0.0281 \mathrm{~F}_{(1 ; 22)} 1.22$; Figure $\left.4 \mathrm{~B}\right)$.

\section{Generation of nigral NG2 ${ }^{+}$cells in MPTP-mice induced by} RUN and ENR depends on the presence of dopamine

In the next step we analysed the role of activity and levodopa on the numbers of new NG2+ cells in the SN. Except for the short-term exercise group (one-way ANOVA: $\left.p=0.0134, \mathrm{~F}_{(29 ; 98)}: 18.4\right)$ and the 70 days exercise group (one-way ANOVA: $p=0.0054 \mathrm{~F}_{(29 ; 98)}$ : 18.4 ) all healthy controls exposed to RUN and ENR showed an increase in the numbers of $\mathrm{BrdU}^{+} / \mathrm{NG}^{+}$cells in the $\mathrm{SN}$ compared to controls under standard housing conditions (one-way ANOVA: 3d: $p=0.04,10 \mathrm{~d}: p=0.036, p<0.001,28 \mathrm{~d}: p<0.001,70 \mathrm{~d}$ : $p=0.007 \mathrm{~F}_{(29 ; 98)}: 18.4$, Figure $\left.4 C\right)$.

In MPTP-treated mice, ENR and RUN increased the numbers of newborn $\mathrm{NG}^{+}$cells only in the short term group (one-way ANOVA: $p<0.001, \mathrm{~F}_{(29 ; 98)}: 18.4$ ). These differences were no longer apparent at later time points (Figure 4D). When MPTP-treated mice received levodopa for 10 days, there was a significant main effect for levodopa (three-way ANOVA: $\mathrm{F}_{(1 ; 41)} 34.65, p<0.001$ ), a significant interaction effect between levodopa-treatment and MPTPtreatment (three-way ANOVA: $\mathrm{F}_{(1 ; 41)} 59.1, p<0.001$ ) and a significant interaction effect between levodopa, physical stimulation and MPTP (three way ANOVA_ $\mathrm{F}_{(2 ; 21)}$ 6.13, $p=0.005$ ). This indicates that the effect of physiological stimulation on $\mathrm{BrdU}^{+} / \mathrm{NG}^{+}$nigral cells in MPTP mice depends on levodopa treatment. In controls, levodopa treatment had no effects (two-way ANOVA: $F_{(1 ; 20)}$ 2.29, $p=0.146$; Figure 4E). 


\section{A}

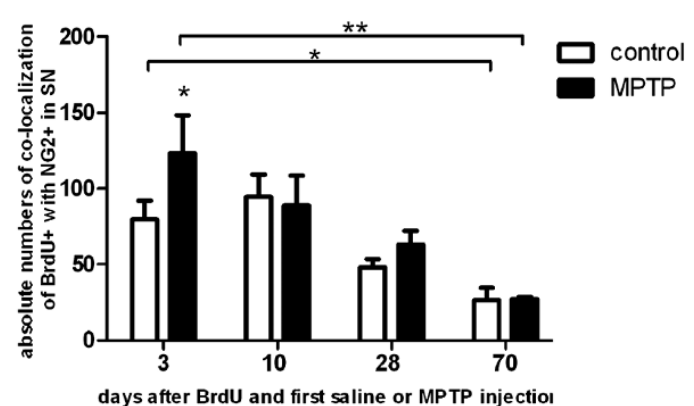

C

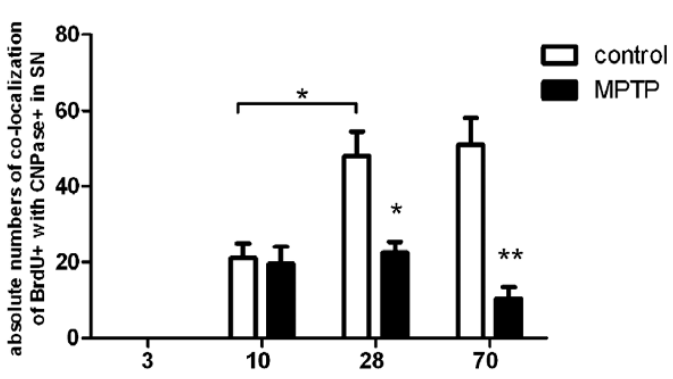

days after BrdU and first saline or MPTP injection

E

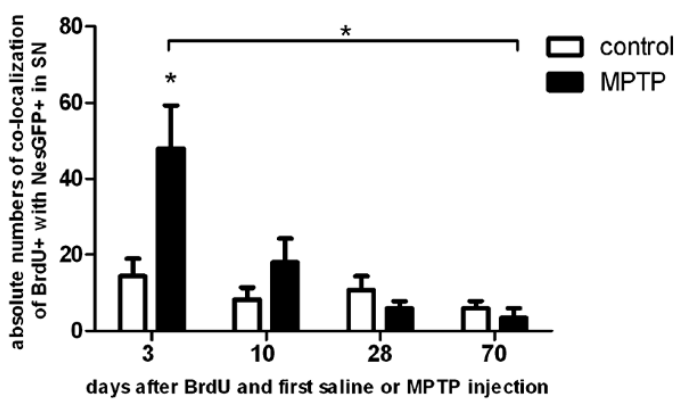

B

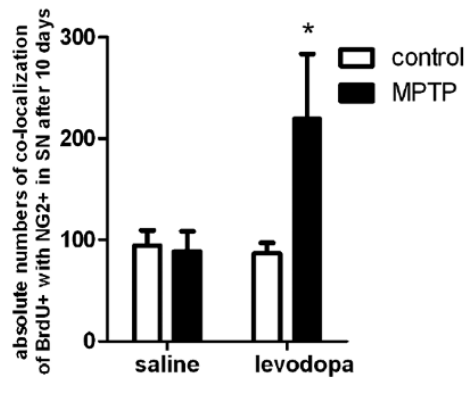

D

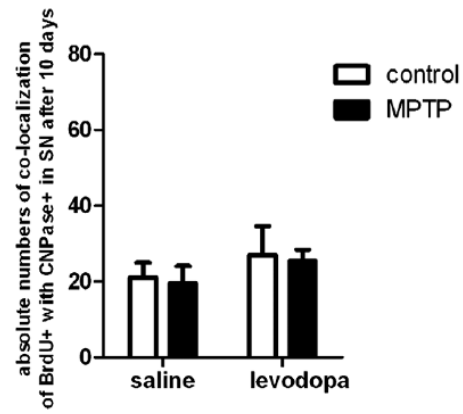

$\mathbf{F}$

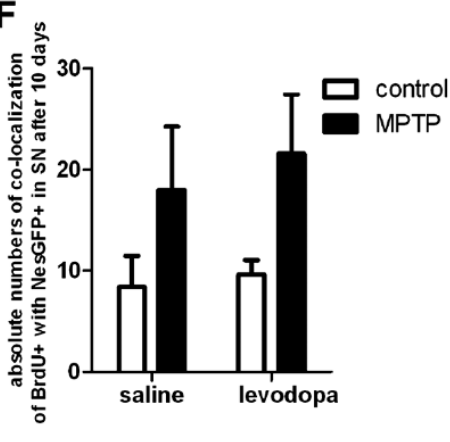

Figure 3 Histological analysis and quantification of the absolute numbers of co-localization of BrdU-positive cells with $\mathrm{NG2}^{+}$cells, CNPase $^{+}$mature oligodendrocytes and nestin-GFP ${ }^{+}$neural precursors in the SN. Effects of 10 days of levodopa treatment. A: In short term groups MPTP induced a significant increase in the number of co-labeled $\mathrm{BrdU}^{+}$and $\mathrm{NG} 2+$ in the $\mathrm{SN}$ compared to saline-treated controls. At later time points this effect was not detectable. The numbers of co-labeled $\mathrm{BrdU}^{+}$and $\mathrm{NG} 2+$ cells decreased over time in controls and MPTP groups. B: At day 10 the number of co-labeled BrdU ${ }^{+}$and NG2+ cells was significantly increased in MPTP mice that were treated with levodopa. C: After 3 days no newborn mature oligodendrocytes were detectable. In 28- and 70 day groups MPTP induced a decrease in co-labeled BrdU ${ }^{+}$and CNPase+ cells compared to saline treated controls where an increase in CNPase+ cells was observed between 10 and 28 days. D: At day 10 the number of $\mathrm{BrdU}^{+}$-labeled mature oligodendrocytes was not influenced by MPTP or levodopa. There was no significant interaction between levodopa treatment and MPTP-treatment. E: In short term groups MPTP induced a significant increase in the number of BrdU ${ }^{+}$neural precursors (Nes-GFP-positive, Nes-GFP+) in the SN compared to saline-treated controls. In later groups no such effect was detectable. The number of newborn NesGFP+ cells decreased over time in MPTP groups. F: At day 10 the number of BrdU ${ }^{+}$neural precursors was not influenced by MPTP or levodopa. There was no significant interaction between levodopa treatment and MPTP-treatment. ${ }^{*} p<0.05$, ${ }^{* *} p<0.001$ versus corresponding controls, $\left.\left.\Gamma^{*}\right\urcorner p<0.05, \Gamma^{* *}\right\urcorner p<0.001$ versus other groups $(n \geq 5)$.

\section{Disturbed oligodendrogenesis following MPTP is not} affected by physiological stimuli or levodopa

The numbers of newly generated $\mathrm{CNPase}+/ \mathrm{BrdU}^{+}$cells were not changed by physical activity in any groups. In controls after 28 days of exposure to an enriched environment a transient increase in new $\mathrm{CNPase}^{+}$cells could be detected but the differences to the standard housing conditions were not significant over time (one-way ANOVA: $10 \mathrm{~d}: p=0.04, p=0.99,28 \mathrm{~d}: p=0.62$, $p=0.18$, 70d: $\left.p=0.5, p=0.32, \mathrm{~F}_{(23 ; 73)}: 6.7\right)$. In MPTP mice 


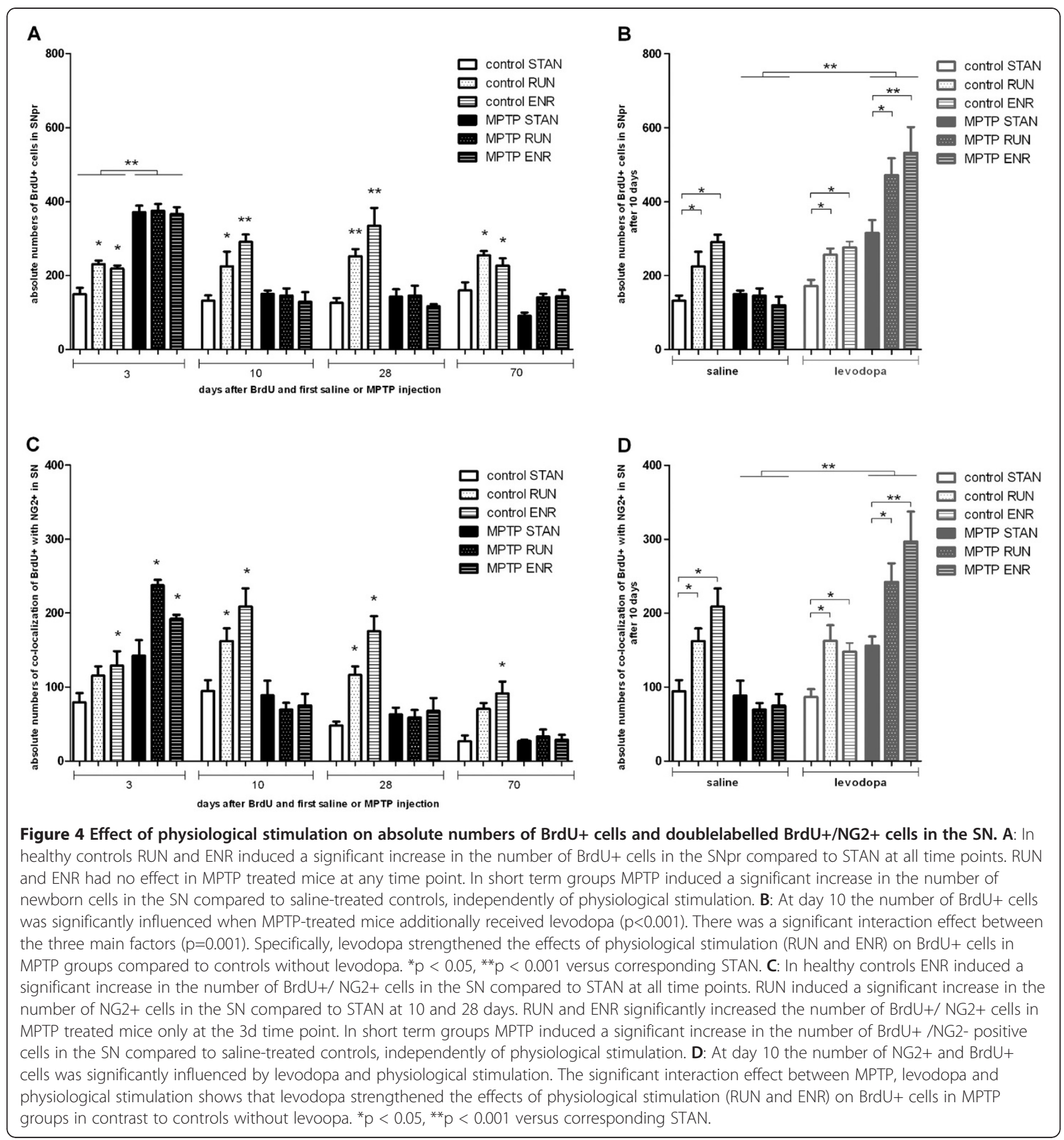

oligodendrogenesis was not susceptible to physiological stimulation. We neither detected a main effect of physiological stimulation (two-way ANOVA: $\mathrm{F}_{(2 ; 18)}$ $0.45, p=0.64$ ) nor an interaction effect between levodopa and physiological stimulation on the numbers of $\mathrm{CNPase}^{+} / \mathrm{BrdU}^{+}$cells (two-way ANOVA: $\mathrm{F}_{(2 ; 18)}$ 1.4, $p=0.27)$. Levodopa had no effect on $\mathrm{CNPase}^{+} / \mathrm{BrdU}^{+}$ cells (two-way ANOVA: $\mathrm{F}_{(1 ; 18)} 3.1, p=0.094$ ).
The in vivo increase of Nestin-GFP ${ }^{+}$cells is also reflected in neurosphere-forming cells in vitro

To investigate whether the short term increase of nestin-GFP ${ }^{+}$cells within the SN after 3 days post MPTP in vivo translates into an appearance or increase of neurosphere-forming NPCs in vitro as a potential restorative capacity of this cell population, we quantitatively analysed the number of isolable NPCs within the 
SVZ as well as the SN using the technology introduced by Lefkovits and optimized for the selection of multipotent adult NPCs [3,30,31]. Neurospheres with identical morphology could be detected after 7-10 days in vitro independently of the brain's region of origin. Quantitative colony forming assays revealed an extreme low occurrence of neurosphere-forming cells within the SN (approx. 1 colony-forming cells out of 10,000 isolated cells) with no differences between MPTP-treated and control animals in any brain region (Figure 5). NPCs of the SVZ of both controls and MPTP-treated animals did not show any differences in morphology, nestin-GFP expression (Figure 5) or NPC marker expression (Olig2, Sox2, NG2; data not shown). Of note, proliferation-frequencies of isolated NPCs from the SN were so rare and long-term culture over two weeks and subsequent further characterizations were not possible.

\section{No newborn neurons, astrocytes or endothelial cells were} found in the $\mathrm{SN}$ at any time point

We analysed the phenotypic distribution of newly generated $\mathrm{BrdU}^{+}$cells in the $\mathrm{SN}$ at all time points following MPTP treatment. Laser confocal microscopy permitted to evaluate the colocalization and quantification of proliferated cells with immature and mature neuronal, glial, and endothelial markers (Nestin-GFP, DCX, NeuN, TH, S100ß, GFAP, NG2, CNPase, Iba1, vWF, CD31). No coexpression of immature (DCX) or mature neuronal markers (NeuN) with BrdU was found at any time point. No proliferated astrocytes (GFAP) or endothelia (anti-vWF) were located in the $\mathrm{SN}$ either.

\section{MPTP induced decrease in TH-immunoreactivity in the SNpc is not reversible by levodopa treatment}

To assess the effect of MPTP treatment on dopamine depletion in the SN we quantified TH-expressing dopaminergic neurons in the $\mathrm{SN}$ at 3, 10, 28 and 70 days after the first MPTP injection (see Figure 6 for experimental design). MPTP-treated animals showed a significant decrease of TH-expressing cell counts compared to saline-treated controls at all analysed time points (Figure 7; one-way ANOVA: $p<0.001 \mathrm{~F}_{(9 ; 42)}$ : 19.8). After 70 days, $\mathrm{TH}$-immunoreactive cell numbers in MPTP treated mice were increased compared to the cell numbers in MPTP mice after 10 days (one-way ANOVA: $\left.p=0.023 ; \mathrm{F}_{(9 ; 42)}: 19.8\right)$. Ten days of levodopa treatment had no effect on the TH-expression, neither in MPTP treated animals, nor in controls (Figure 7; one-wayANOVA: $p=0.671, p=0.502$ ANOVA, $\mathrm{F}_{(9 ; 42)}$ : 19.8). Physical activity (RUN) and environmental enrichment (ENR) had no effect on TH-positive cell numbers at any time (data not shown).

\section{Discussion}

Although the adult SN lacks the capacity to generate dopaminergic neurons, generation of non-neuronal cells has been robustly shown in the adult nigra $[5,6]$. The origin and functional role of these cells are still under debate [3]. These cells mainly express the neuro-glial antigen NG2, which marks oligodendrocytic precursors and also a number of cells with the potential to differentiate into neurons or microglia $[19,26,27,29]$. The main hallmark of PD is dopaminergic neurodegeneration in the $\mathrm{SN}$ and the goal for potential restorative therapies in the future might be the replacement of dying tissue by potential neural precursors. We asked, if the generation and differentiation of nigral NG2+ cells depends on dopamine and if and how physical activity and environmental enrichment would influence these cell populations and their potential differentiation. In the first step we quantified all BrdU+ cells in the SNpc and SNpr. As we found that in both areas the numbers of BrdU+ cells were equally significantly increased following MPTP but the absolute numbers of these cells were very low, we did not further differentiate between $\mathrm{SNpc}$ and SNpr in the phenotypic analyses of BrdU+ cells. The small numbers of BrdU+ cells in the SN might be due to the usage of only one proliferation marker and its systemic application. Other groups reported the local, intrastrial application of BrdU and consecutively higher numbers of labelled cells [4]. However, intrastriatal application requires a surgical intervention which per se already induces changes in the local microenvironment and might be responsible for changes in the numbers of newborn cells. Thus, the de facto number of BrdU+ cells in the SN might be higher than detected by our methods. The analyses of all BrdU+ cells in the SN over time showed an initial significant increase in the numbers of BrdU+ cells in MPTP-treated mice compared to controls. Within a few days the numbers decrease significantly indicating an initial transitory reactive cell proliferation following the lesion. This hypothesis is supported with the finding, that a large number of these cells were microglia at this time-point and the percentage of microglial cells of all BrdU+ cells did not play a role at any later time point or treatment. One could assume, that after an initial activation these cells either die or migrate away from the lesion site. This migrationhypothesis at the early time point in MPTP-mice would also support the finding, that in healthy control animals the numbers of BrdU+ cells remain stable over a long period of time (70 days in our study) without a significant effect of e.g. aging on the numbers of BrdU+ cells in the SN.

Regarding the phenotypic distribution we found a significant number of the newborn nigral cells coexpressing NG2. These cells were robustly regulated by 
A
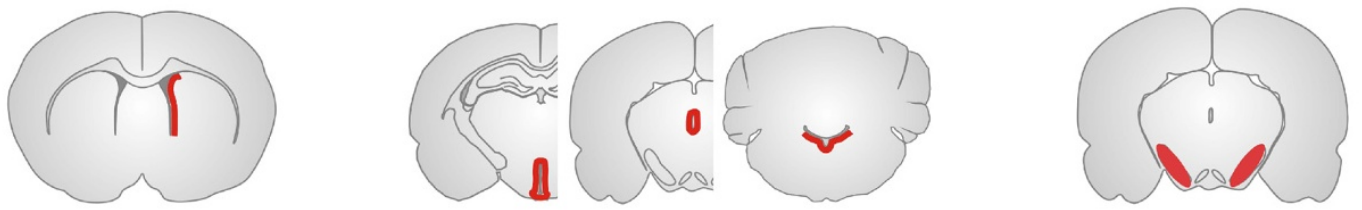

B
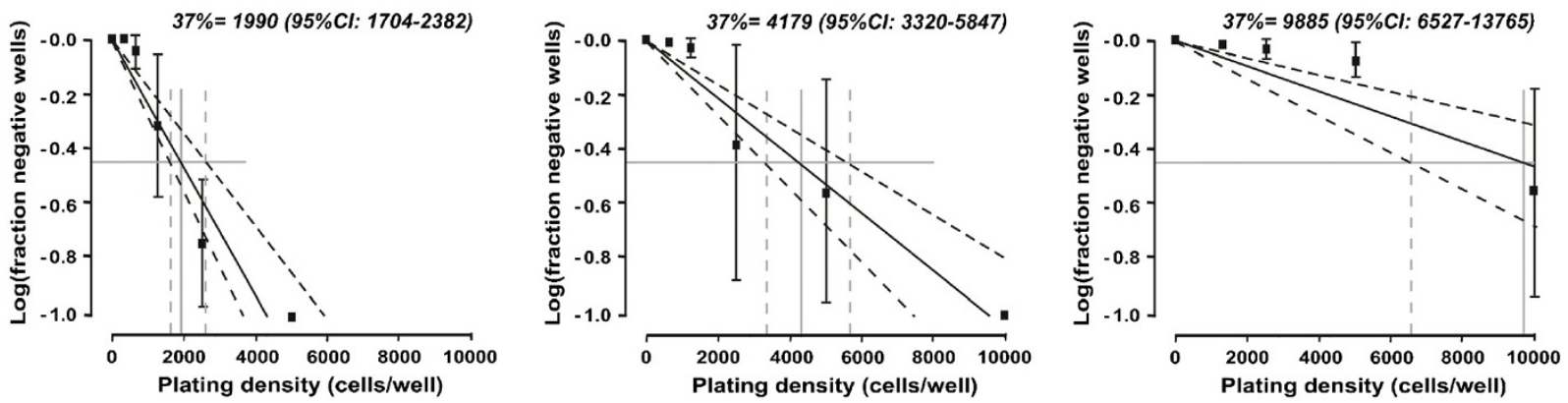

C
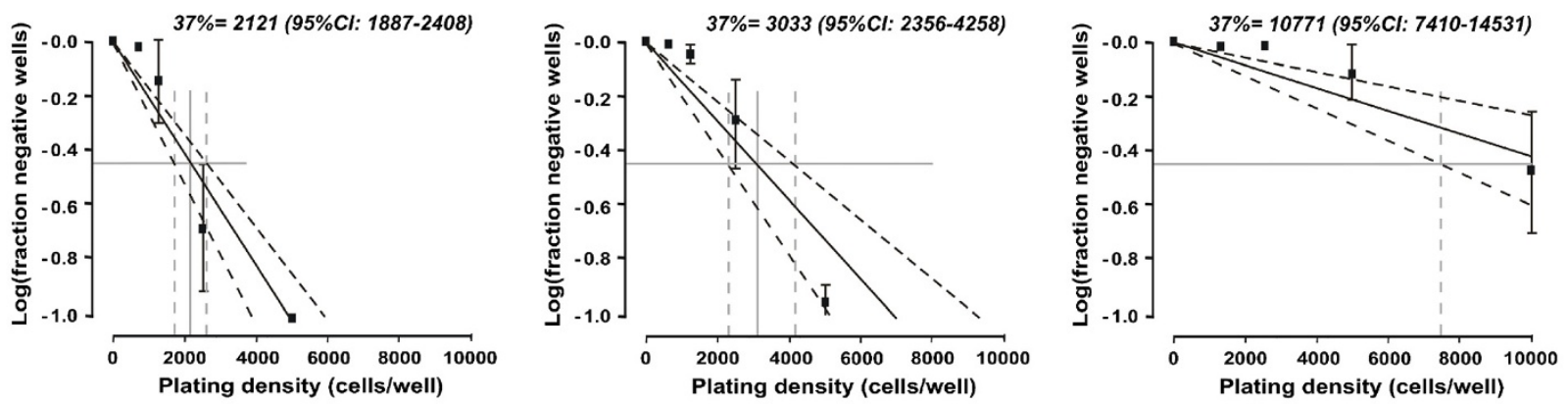

D
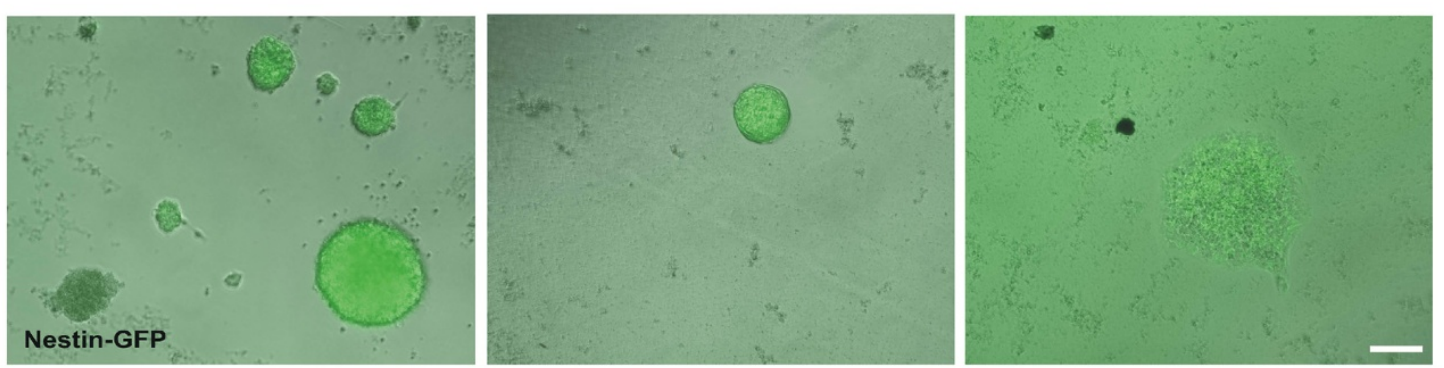

$\mathbf{E}$
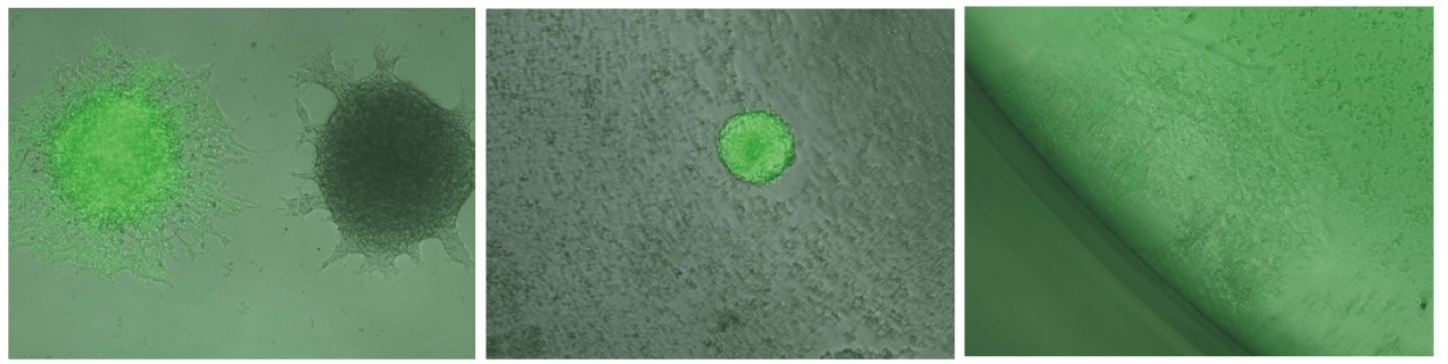

Figure 5 In vitro characterization of NPCs derived from microdissected periventricular regions throughout the brain. A: Schematic brain images showing the regions which were microdissected for NPC culture. B: Limiting dilution assay for primary neurospheres from different regions of control mice are shown $(n=3)$. C: Limiting dilution assay for primary neurospheres from different regions of MPTP-treated mice are shown ( $\mathrm{n}=3-6)$. Data are shown as mean \pm SEM, dotted lines represent $95 \%$ confidence interval $(95 \% \mathrm{Cl})$. The intercept of log (37\% negative wells) gave the neurosphere-forming frequency. D-E: Representative neurospheres of NesGFP mice are depicted after one week of expansion of control (D) and MPTP-treated animals (E). Scale bar, $100 \mu \mathrm{m}$. 


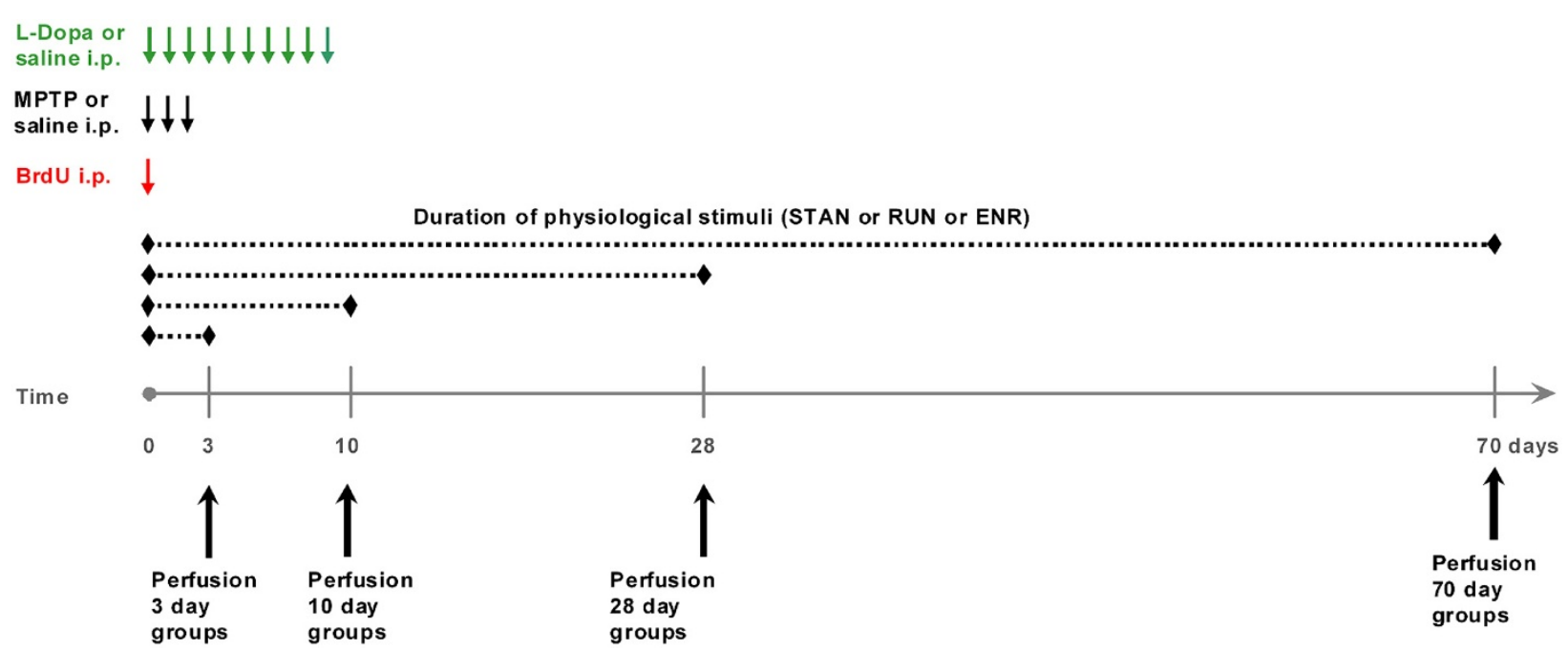

Figure 6 Schematic representation of the experimental design.
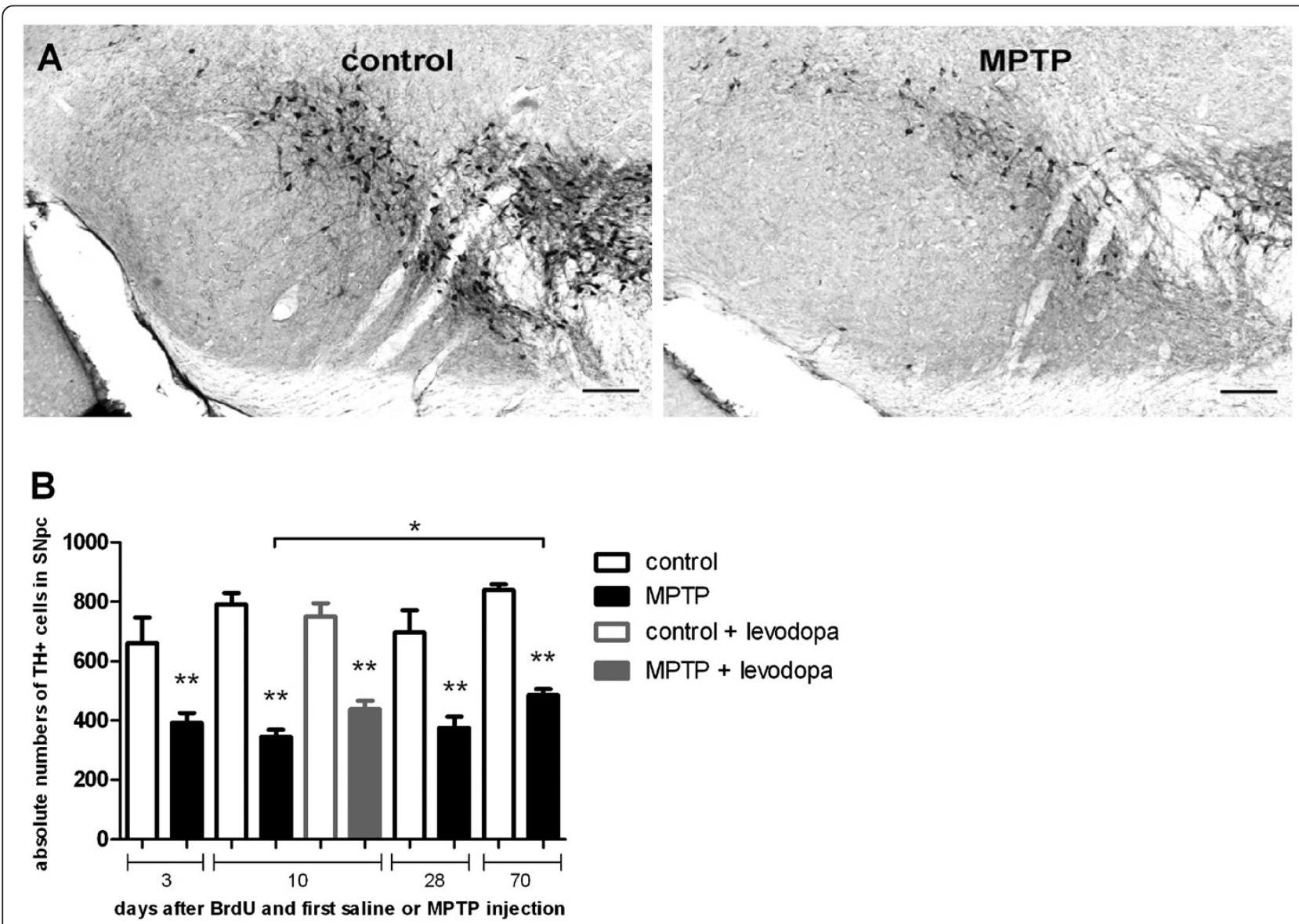

Figure 7 Histological analysis and quantification of MPTP-induced degeneration of Tyrosinhydroxylase-positive $\left(\mathrm{TH}^{+}\right)$dopaminergic neurons in the substantia nigra (SN). A: TH-expressing dopaminergic neurons in the SN detected by immunohistochemistry. Representative coronal

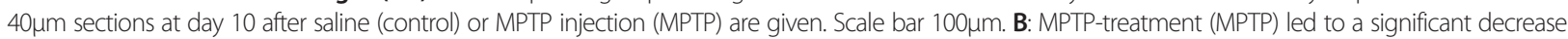
in the numbers of $\mathrm{TH}^{+}$dopaminergic neurons in the $\mathrm{SN}$ at all time points compared to controls (control). In MPTP-treated animals there was a recovery in the numbers of $\mathrm{TH}^{+}$neurons after 70 days compared to 10 days. 10 days of levodopa-treatment had no effect on MPTP- treated groups (L-Dopa MPTP) or healthy controls (L-Dopa control). ${ }^{*} p<0.05,{ }^{* *} p<0.001$ versus corresponding control (values from LSD post-hoc tests). 
physiological stimuli in healthy animals as expected from previous work $[6,14,15]$. In contrast to studies in the 6OHDA PD rat model, we did not detect an influence of activity on the numbers of $\mathrm{NG}^{+}$cells of parkinsonian MPTP-treated mice. This might be mainly explained by species and animal model differences. Not till additional treatment with levodopa as dopamine rescue, nigral $\mathrm{NG}^{+}$cell proliferation in mice with access to physical activity or environmental enrichment was significantly enhanced. These results suggest a function for dopamine in activity-induced $\mathrm{NG}^{+}$cell generation. If these new cells could in the end indeed play a role in neuronal restoration following dopaminergic neurodegeneration remains to be clarified, but their reactive proliferation following MPTP and their vulnerability to physiological stimuli and dopamine suggests a potential function role in the dopamine-depleted brain.

Therefore, in the next step, we were interested if activity had also a dopamine-dependent effect on long-term maturation of $\mathrm{NG}^{+}$cells. The majority of the $\mathrm{NG}^{+}$cells in the adult brain in vivo are oligodendrocytic precursors $[32,33]$, but $\mathrm{NG}^{+}$cells in the SN were also described to maturate into microglia or in vitro into neurons and secrete neurotrophic factors as a potential endogenous neuroprotective mechanism following neurodegeneration $[19,29,34]$. The numbers of $\mathrm{NG}^{+}$cells in our study decreased significantly over time. This decline implicates a physiological differentiation process of $\mathrm{NG}^{+}$cells into mature oligodendrocytes or other resident cell types in the healthy SN. We thus quantified the numbers of $\mathrm{BrdU}+$ nigral oligodendrocytes by CNPase-expression over time depending on MPTP-treatment and physiological stimulation. In the short-term MPTP- and saline-treated groups, no $\mathrm{CNPase}^{+}$cells were detected indicating the appearance of mature cell populations rather at later time points. The first $\mathrm{BrdU}^{+} / \mathrm{CNPase}^{+}$ cells in the SN were detected 10 days after MPTP or saline in both groups supporting the hypothesis of an ongoing maturation process. In controls the numbers of new CNPase ${ }^{+}$cells increased over time in line with a continuous decrease of $\mathrm{NG}^{+}$cell numbers. In contrast, MPTP-treated animals showed unchanged numbers of new $\mathrm{CNPase}^{+}$cells in the $\mathrm{SN}$, despite a continuous decrease of $\mathrm{NG}^{+}$cells as a possibly sign of a disturbed oligodendrocyte maturation process in the SN following dopamine depletion in line with previous studies showing disturbances in oligodendrocytic homeostasis following MPTP [21]. Another reason for the decrease of $\mathrm{NG}^{+}$cells in MPTP mice and a lack of increase of CNPase+ cells could be the maturation of $\mathrm{NG}^{+}$cells in other neural cell types, but also changes due to the aging brain between the earliest and latest time points of our investigations. However, in our model we did not observe any $\mathrm{BrdU}^{+}$cell population increasing over time associated with the $\mathrm{NG}^{+}$cell decrease.

The numbers of CNPase ${ }^{+}$oligodendrocytes were not altered by physiological stimulation or levodopa rescue in any group and at any time point. As activity robustly increases functionally relevant neurogenesis in neurogenic regions of the healthy brain [35,36], our data add somewhat to the differentiation between neurogenic and non-neurogenic regions and also show a different regulation of nigral cells following physiological stimuli and pharmacological treatment in line with comparable data from the dentate gyrus [13]. In the $\mathrm{SN}$ activity regulated cellular plasticity might occur on precursor cell level, however the stimulus is not sufficient to induce or enhance the further maturation process of these cells. This might be of interest in the context of a suggested neuroprotective role for oligodendrocytes in the lesioned SN most likely by protective factor secretion [37].

The maturation of $\mathrm{NG}^{+}$cells into microglia with neuroprotective capacities has been discussed recently [19]. Apart from a reactive general glia proliferation 3 days after MPTP, we did not detect any significant changes of Iba1-positive microglia or other glial cells in any group at any time point in this present study. To address if other neural precursors are generated in the $\mathrm{SN}$ in a dopamine or activity dependent manner, we applied MPTP to transgenic Nestin-GFP mice and visualised new neural precursors in vivo $[38,39]$. No relevant increase in the numbers of new Nestin-GFP cells was detectable at any time point and treatment paradigm. This is in agreement with the quantitative colony-forming assay results showing no increase of isolatable NPCs following MPTP treatment for 3 days. The acute and transient increase of Nestin-GFP-cells and Iba-1 positive microglia 3 days after MPTP possibly reflects an unspecific reactive post-toxic proliferation [40-42].

After a primary reduction of $\mathrm{TH}$-immunoreactivity, the numbers of immunohistochemically detectable $\mathrm{TH}^{+}$cells in the MPTP-treated mice increased significantly over time $[43,44]$. The mechanisms underlying this transient degeneration remain widely unclear. No $\mathrm{BrdU}^{+} / \mathrm{TH}^{+}$ neurons have been detected in our study at any time. Thus, the recovery of nigral neurons detected by $\mathrm{TH}$ after MPTP administration might be due to a downregulation of $\mathrm{TH}$-expression on neuronal cells in the SN by MPTP followed by a re-expression of $\mathrm{TH}$ over time, rather than by de facto degeneration of the neurons or reactive proliferation of new dopaminergic neurons. Both, physiological stimuli and levodopa rescue had no effect on $\mathrm{TH}$-expression in the $\mathrm{SN}$ at any time point. One recent report showed forced treadmill-exercise induced increase of the numbers of $\mathrm{TH}^{+}$neurons in the mouse SN [45]. On the other hand, exercise-induced neuroprotection, but no neurogenesis in the $\mathrm{SN}$ was 
reported by others in line with our results [46]. Although one study reported neuronal generation in the SN following MPTP [4], the majority of the studies are in line with our findings of cell proliferation but not neo-neurogenesis in the $\mathrm{SN}[2,5,6]$.

Taken together, the activity-induced generation of $\mathrm{NG}^{+}$precursor cells in the SN critically depends on the presence of dopamine. Based on this data, additional studies will investigate the possible neuro-restorative role of NG2+ nigral cells in PD-brain in dependence of dopamine.

\section{Conclusions}

Physical activity and enriched environment induce generation of newborn cells in the adult mouse SN. The majority of these cells are oligodendrocytic precursors expressing NG2. In the MPTP-model for dopamine depletion the effects of physiological stimuli are suppressed and can be re-activated by levodopa. As $\mathrm{NG}^{+}$cells have been reported to bear neuroprotective and neuroregenerative capacities in the adult, microenvironmental changes in the $\mathrm{SN}$ following activity as a potential future therapeutic strategy in PD should be analysed in future studies based on the present findings.

\section{Methods}

\section{Animals and housing}

All animal experiments were institutionally approved and authorized by the Ethical Committee for Health and Social Care ("Landesamt für Gesundheit und Soziales") Berlin, Germany. Eight to twelve weeks old female transgenic mice, expressing green fluorescent protein under the promoter of nestin on the genetic background of C57Bl6 mice without any CNS or peripheral pathological phenotype, were randomly assigned to groups of minimum $\mathrm{n}=5$ animals and kept at three different housing conditions with a light/dark cycle of 12 hours and free access to food and water [39]. The housing models consisted of 1. standard housing ('STAN') conditions with two mice per cage, 2 . cages with voluntary access to a running wheel ('RUN') with 2 mice per cage, 3 . housing in an 'enriched environment' ('ENR'), with at least 5 mice kept in a cage, $74 \times 74 \mathrm{~cm}$, containing changing food locations, obstacles, places to hide, toys, allowing a stimulation of exploratory behavior and social interaction ([35], Figure 6).

\section{MPTP-model}

1-methyl-4-phenyl-1,2,3,6-tetrahydropyridine

(MPTP, Sigma-Aldrich) was dissolved in $0.9 \% \mathrm{NaCl}$. Half of the mice received 3 intraperitoneal injections of MPTP (20mg/kg body weight) on three consecutive days. Controls were treated with $0.9 \% \mathrm{NaCl}$ for the same time period (Figure 6).

\section{BrdU injection}

Bromodeoxyuridine (BrdU, Sigma-Aldrich) was dissolved in $0.9 \% \mathrm{NaCl}$ and filtered. All mice received one intraperitoneal injection of $\mathrm{BrdU}$ (50mg/ $\mathrm{kg}$ body weight) at the first day of MPTP-injection (Figure 6).

\section{Levodopa treatment}

In order to investigate the effect of dopamine substitution in MPTP-treated animals, these mice received daily doses of levodopa + benserazide (L-Dopa, 20mg/kg + $5 \mathrm{mg} / \mathrm{kg}$, Ferak Berlin + Sigma- Aldrich) for 10 days starting on day 1 of MPTP or $\mathrm{NaCl}$ treatment, respectively. Control mice received $0.9 \% \mathrm{NaCl}$ under the same conditions (Figure 6).

\section{Perfusion and tissue preparation}

Mice were deeply anesthetized with an overdose of ketamine and killed by transcardial perfusion with $4 \%$ paraformaldehyde (PFA) at different time points (day 3, 10, 28 and 70 post MPTP injection). Brains were removed and fixed overnight in PFA at $4^{\circ} \mathrm{C}$ and then transferred in $20 \%$ sucrose for dehydration. Brains were frozen in liquid nitrogen and cut to $40 \mu \mathrm{m}$ coronal sections using a cryostat (Cryocut 1800, Reichert-Jung) and then stored in cryoprotectant at $-20^{\circ} \mathrm{C}$ until histological analysis.

\section{Immunohistochemistry}

For BrdU staining, DNA was denatured in 2N HCL for $30 \mathrm{~min}$ at $37^{\circ} \mathrm{C}$. Sections were treated with $0.6 \% \mathrm{H}_{2} \mathrm{O}_{2}$ to block endogenous tissue peroxidases. Hereafter sections were washed and incubated with $2 \mathrm{~N} \mathrm{HCL}$ for $30 \mathrm{~min}$ at $37^{\circ} \mathrm{C}$ and rinsed in borate buffer and extensively washed with Tris-buffered saline (TBS). Sections were incubated with the primary antibodies (anti-BrdU, rat, 1:500, Biozol; anti-TH, mouse 1:10 000, Sigma- Aldrich) overnight at $4^{\circ} \mathrm{C}$, rinsed in TBS and TBS plus and incubated with the biotinylated secondary antibodies (anti-rat, 1:500, Dianova; anti-mouse, 1:1000, Vector Laboratories) for 2 hours at room temperature. $\mathrm{ABC}$ reagent (Vectastain Elite, Vector Laboratories) was applied for $1 \mathrm{~h}$ at concentration of $9 \mu \mathrm{l} / \mathrm{ml}$. Diaminobenzidine (DAB, SigmaAldrich) was used as a chromogen at a concentration of $0.025 \mathrm{mg} / \mathrm{ml}$ in TBS with $0.01 \% \quad \mathrm{H}_{2} \mathrm{O}_{2}$ and $0.04 \%$ nickel-II-chloride.

\section{Immunofluorescence}

One-in-six series of nigral sections were triple labelled for immunofluorescence. Sections were incubated with the primary antibodies for $24 \mathrm{~h}$ at $4^{\circ} \mathrm{C}$, washed with TBS and TBS plus and incubated with the secondary antibodies for $4 \mathrm{~h}$ at room temperature. Sections were then washed, mounted on slides and coverslipped in polyvinyl alcohol diazabicyclo-octane (PVA-DABCO, SigmaAldrich) as anti- fading agent. The primary antibodies 
were applied in the following concentrations: anti-BrdU (rat, 1:500, Biozol), anti-TH (mouse, 1:10,000, SigmaAldrich), anti-GFP (goat, 1:1000, APC Biermann Acris; rabbit 1:200, Abcam), anti-Iba1 (rabbit, 1:1000, Wako), anti- NG2 (rabbit, 1:200, Chemicon International), antiCNPase (rabbit, 1:1000, Abcam), anti- GFAP (guinea pig, 1:500, Advanced ImmunoChemistry), anti-Doublecortin (goat, 1:200, Santa Cruz Biotechnology), anti-S100-beta (mouse, 1:1000, Sigma-Aldrich), anti- activated Caspase3 ( rabbit 1:150, Abcam), anti-von Willebrand Factor (antivWF, rabbit, 1:250, Abcam). Secondary antibodies used were: anti-rat Rhodamine X, anti-rabbit FITC, anti-rabbit Cy5, anti-mouse Cy5, anti-guinea pig Cy5, anti-mouse Dylight 405 (all 1:250, Dianova), anti-goat FITC (1:100, Dianova), anti-goat Cy5 (1:500, Dianova).

\section{Quantification and imaging}

One in six sections ( $240 \mu \mathrm{m}$ apart) of each brain of all DAB stained animals was counted for BrdU- and THpositive cells throughout the substantia nigra both, the pars compacta and pars reticulata (SN) bilaterally using a Leica DM RXE microscope. The boundaries of the SN were determined with reference to internal anatomic landmarks using a mouse atlas (The Mouse Brain in Stereotaxic Coordinates, Paxinos 2007) The substantia nigra pars compacta and pars reticulata were delineated at $10 \mathrm{x}$ magnification with reference to internal anatomic landmarks. Tyrosine hydroxylase immunostaining was used to approximate the border between the compacta and reticulata area. The SN was outlined in every section using the 10x objective. Actual counting was done using the $40 x$ objective. Resulting numbers were then multiplied by six in order to estimate the total number of stained cells per SN. For immunofluorescence, all BrdUpositive cells in the SN (minimum 18 cells) were analyzed for co-expression of glial, neuronal or vascular markers using a confocal laser scanning microscope (Leica DM 2500) under a 40x- or 63x objective. Absolute numbers and ratios of double- or triple-labelled cells versus BrdU-positive cells are given. All images were taken in sequential scanning mode and further processed in Adobe Photoshop 7.0. Only general contrast adaptations were made and figures were not otherwise manipulated. Exemplary and representative images are presented.

\section{Statistical analysis}

All cell numbers are given as mean with standard errors of the mean (S.E.M). All numerical analysis were performed using SPSS 19. For comparisons one-, two-, and three-way ANOVA was performed, followed by LSD post hoc test when appropriate. In one-way ANOVA the factor was 'groups', in two-way ANOVA the factors were MPTP treatment (control vs MPTP) and L-dopa treatment (saline vs levodopa) and in three-way ANOVA the factors were MPTP treatment (control vs MPTP), L-dopa treatment (saline vs levodopa) and physiological stimulation (STAN vs RUN vs ENR). Differences were considered statistically significant at $\mathrm{p}<0.05$.

\section{Neurosphere cultures}

Mice were killed by cervical dislocation, their brains removed and placed in ice-cold Hank's balanced salt solution (HBSS) supplemented with $1 \%$ penicillin/strepomycin and $1 \%$ glucose (all from Gibco, Tulsa, OK). Whole brains were cut into coronal sections of approximately $500 \mu \mathrm{m}$ and the $\mathrm{SN}$ (defined as remaining tissue of the midbrain/ hindbrain region after removal of cerebellum and ventricular zones of third ventricle, Aq, fourth ventricle), as well as the periventricular region of the lateral ventricle (LV, lateral wall) was then aseptically prepared. Expansion of neurospheres was carried out for a maximum of 2 weeks before further characterization [31]. Limiting dilution experiments were done as described by Bull and Bartlett [47]. In brief, primary cells were plated at reducing densities in 96-well plates (BD Biosciences, Australia) with $200 \mu \mathrm{l}$ per well in Neurobasal ${ }^{\circledR}$ medium supplemented with $1 \%$ glutamate, $2 \%$ B27 and 1\% penicillin/strepomycin containing 20ng/ml EGF (epidermal growth factor) and FGF-2 (fibroblast growth factor 2). Cell suspensions were diluted by serial 1:2 dilutions and cells were plated at 5 to 20,000 cells per well. After 7 days in vitro, the fraction of wells negative for neurosphere formation was quantified. These data were then log transformed passing through zero fitted to the data (including the 95\% confidence intervals (95\%CIs) using the Origin 5.0 software. The intercept of $\log (37 \%)$ gave the frequency of cells capable of proliferating to form a neurosphere $[3,30,31]$.

\section{Authors' contribution}

PK performed the animal experiments and wrote the manuscript. AL analysed the in vivo material. PH performed the statistical analyses and participated in histological analyses. $\mathrm{AH}$ and $\mathrm{AS}$ performed the in vitro study and helped to draft the manuscript. BS participated in the in vivo and in vitro analyses, designed the study and wrote the manuscript. All authors read and approved the manuscript.

\section{Acknowledgements}

The authors thank Jennifer Altschüler and Renate Winter for excellent technical assistance. The study was funded by the Else Kröner-FreseniusStiftung to B.S. B.S. is a Rahel Hirsch fellow of the Charité University Medicine Berlin.

\section{Author details}

'Department of Neurology, Charité University Medicine Berlin; CCM, Charitéplatz 1, Berlin 10117, Germany. 'Department of Neurology; Division of Neurodegenerative Diseases, Dresden University of Technology, Dresden 01307, Germany. ${ }^{3}$ Center for Regenerative Therapies Dresden (CRTD), Dresden 01307, Germany. ${ }^{4}$ German Center for Neurodegenerative Diseases (DZNE), Research Site Dresden, Dresden 01307, Germany.

Received: 7 August 2012 Accepted: 14 October 2012

Published: 31 October 2012 


\section{References}

1. Hirsch E, Graybiel AM, Agid YA: Melanized dopaminergic neurons are differentially susceptible to degeneration in Parkinson's disease. Nature 1988, 334(6180):345-348.

2. Frielingsdorf $H$, Schwarz K, Brundin P, Mohapel P: No evidence for new dopaminergic neurons in the adult mammalian substantia nigra. Proc Natl Acad Sci USA 2004, 101:10177-10182.

3. Hermann A, Suess C, Fauser M, Kanzler S, Witt M, Fabel K, Schwarz J, Höglinger GU, Storch A: Rostro-caudal gradual loss of cellular diversity within the periventricular regions of the ventricular system. Stem Cells 2009, 27(4):928-941.

4. Zhao M, Momma S, Delfani K, Carlen M, Cassidy RM, Johansson CB, Brismar $H$, Shupliakov O, Frisen J, Janson AM: Evidence for neurogenesis in the adult mammalian substantia nigra. Proc Natl Acad Sci USA 2003, 100:7925-7930.

5. Lie DC, Dziewczapolski G, Willhoite AR, Kaspar BK, Shults CW, Gage FH: The adult substantia nigra contains progenitor cells with neurogenic potential. J Neurosci 2002, 22:6639-6649.

6. Steiner B, Winter C, Hosman K, Siebert E, Kempermann G, Petrus DS, Kupsch $A$ : Enriched environment induces cellular plasticity in the adult substantia nigra and improves motor behaviour function in the 6-OHDA rat model of Parkinson's disease. Exp Neurol 2006, 199:291-300.

7. Freundlieb N, François C, Tandé D, Oertel WH, Hirsch EC, Höglinger GU: Dopaminergic substantia nigra neurons project topographically organized to the subventricular zone and stimulate precursor cell proliferation in aged primates. J Neurosci 2006, 26(8):2321-2325.

8. He XJ, Yamauchi H, Uetsuka K, Nakayama H: Neurotoxicity of MPTP to migrating neuroblasts: studies in acute and subacute mouse models of Parkinson's disease. Neurotoxicology 2008, 29(3):413-420.

9. Höglinger GU, Rizk P, Muriel MP, Duyckaerts C, Oertel WH, Caille I, Hirsch EC: Dopamine depletion impairs precursor cell proliferation in Parkinson disease. Nat Neurosci 2004, 7:726-735.

10. $\mathrm{Mu}$ Y, Zhao C, Gage FH: Dopaminergic modulation of cortical input during maturation of adult-born dentate granule cells. J Neurosci 2011 , 31(11):4113-4123.

11. Shan X, Chi L, Bishop M, Luo C, Lien L, Zhang Z, Liu R: Enhanced de novo neurogenesis and dopaminergic neurogenesis in the substantia nigra of MPTP- induced Parkinson's disease- like mice. Stem Cells 2006, 24:12801287.

12. Borta A, Höglinger GU: Dopamine and adult neurogenesis. J Neurochem 2007, 100(3):587-595.

13. Steiner B, Kronenberg G, Jessberger S, Brandt MD, Reuter K, Kempermann G: Differential regulation of gliogenesis in the context of adult hippocampal neurogenesis in mice. Glia 2004, 46:41-52.

14. Steiner B, Zurborg S, Hörster H, Fabel K, Kempermann G: Differential 24h responsiveness of Prox1-expressing precursor cells in adult hippocampal neurogenesis to physical activity, environmental enrichment, and kainic acid-induced seizures. Neurosci 2008, 154(2):521-529.

15. Kronenberg G, Reuter K, Steiner B, Brandt MD, Jessberger S, Yamaguchi M, Kempermann G: Subpopulations of proliferating cells of the adult hippocampus respond differently to physiologic neurogenic stimuli. $J$ Comp Neurol 2003, 467:455-463.

16. Ehninger D, Wang LP, Klempin F, Römer B, Kettenmann H, Kempermann G: Enriched environment and physical activity reduce microglia and influence the fate of NG2 cells in the amygdala of adult mice. Cell Tissue Res 2011, 345(1):69-86

17. Fabel K, Wolf SA, Ehninger D, Babu H, Leal-Galicia P, Kempermann G: Additive effects of physical exercise and environmental enrichment on adult hippocampal neurogenesis in mice. Front Neurosci 2009, 3:50.

18. Huehnchen P, Prozorovski T, Klaissle P, Lesemann A, Ingwersen J, Wolf SA, Kupsch A, Aktas O, Steiner B: Modulation of adult hippocampal neurogenesis during myelin-directed autoimmune neuroinflammation. Glia 2011, 59(1):132-142.

19. Kitamura $Y$, Inden M, Minamino H, Abe M, Takata K, Taniguchi T: The 6-hydroxydopamine-induced nigrostriatal neurodegeneration produces microglia-like NG2 glial cells in the rat substantia nigra. Glia 2010, 58(14):1686-1700.

20. Sortwell CE, Daley BF, Pitzer MR, McGuire SO, Sladek JR Jr: Collier TJ: Oligodendrocyte-type 2 astrocyte-derived trophic factors increase survival of developing dopamine neurons through the inhibition of apoptotic cell death. J Comp Neurol 2000, 426(1):143-143.
21. Takagi S, Hayakawa N, Kimoto H, Kato H, Araki T: Damage to oligodendrocytes in the striatum after MPTP neurotoxicity in mice. J Neural Transm 2007, 114(12):1553-1557.

22. Wakabayashi K, Hayashi S, Yoshimoto M, Kudo H, Takahashi H: NACP/alpha-synuclein-positive filamentous inclusions in astrocytes and oligodendrocytes of Parkinson's disease brains. Acta Neuropathol 2000, 99(1):14-20

23. Anastasia A, Torre L, de Erausquin GA, Mascó DH: Enriched environment protects the nigrostriatal dopaminergic system and induces astroglial reaction in the 6-OHDA rat model of Parkinson's disease. J Neurochem 2009, 109(3):755-765

24. Garland T Jr, Schutz H, Chappell MA, Keeney BK, Meek TH, Copes LE, Acosta W, Drenowatz C, Maciel RC, van Dijk G, Kotz CM, Eisenmann JC: The biological control of voluntary exercise, spontaneous physical activity and daily energy expenditure in relation to obesity: human and rodent perspectives. J Exp Biol 2011, 214(Pt2):206-229.

25. Yuan ZY, Gu P, Liu L, Wang YY, Liu J, Cui DS, Geng Y, Zhang ZX, Zhu AP, Ma L, Wang MW: Neuroprotective effects of enriched environment in MPTP-treated SAMP8 mice. Neurosci Lett 2009, 454(1):6-10.

26. Aguirre AA, Chittajallu R, Belachew S, Gallo V: NG2-expressing cells in the subventricular zone are type C-like cells and contribute to interneuron generation in the postnatal hippocampus. J Cell Biol 2004, 165(4):575-578.

27. Belachew S, Chittajallu R, Aguirre AA, Yuan X, Kirby M, Anderson S, Gallo V: Postnatal NG2 proteoglycan-expressing progenitor cells are intrinsically multipotent and generate functional neurons. J Cell Biol 2003, 161(1):169-186

28. Nishiyama A, Lin XH, Giese N, Heldin CH, Stallcup WB: Co-localization of NG2 proteoglycan and PDGF alpha-receptor on O2A progenitor cells in the developing rat brain. J Neurosci Res 1996, 43(3):299-314.

29. Nishiyama A, Komitova M, Suzuki R, Zhu X: Polydendrocytes (NG2 cells): multifunctional cells with lineage plasticity. Nat Rev Neurosci 2009, 10(1):9-22.

30. Lefkovits I: Limitting dilution analysis of cells in the immune system. Cells in the immune system. Cambridge; 1979:8-10.

31. Hermann A, Maisel M, Wegner F, Liebau S, Kim DW, Gerlach M, Schwarz J, Kim KS, Storch A: Multipotent neural stem cells from the adult tegmentum with dopaminergic potential develop essential properties of functional neurons. Stem Cells 2006, 24(4):949-964.

32. Dimou L, Simon C, Kirchhoff F, Takebayashi H, Götz M: Progeny of Olig2- expressing progenitors in the gray and white matter of the adult mouse cerebral cortex. J Neurosci 2008, 28(41):10434-10442.

33. Karram K, Chatteriee N, Trotter J: NG2-expressing cells in the nerbvous system: role of the proteoglycan in migration and glial-neuron interaction. J Anat 2005, 207(6):735-744.

34. Hermann A, Brandt M, Loewenbruck K, Storch A: Silenced polydendrocytes: A new cell type within the oligodendrocyte progenitor cell proliferation? Cell Tissue Res 2010, 340(1):45-50.

35. Kempermann G, Kuhn HG, Gage FH: More hippocampal neurons in adult mice living in an enriched environment. Nature 1997, 386(6624):493-495.

36. van Praag $H$, Kempermann G, Gage FH: Running increases cell proliferation and neurogenesis in the adult mouse dentate gyrus. Nat Neurosci 1999, 2:266-270.

37. Mena MA, Garcia de Yébenes J: Glial cells as players in parkinsonism: the2good", the "bad", and the "mysterious" glia. Neuroscientist 2008, 14(6):544-560.

38. Lendahl U, Zimmermann LB, McKay RD: CNS stem cells express a new class of intermediate filament protein. Cell 1990, 60(4):585-595.

39. Yamaguchi M, Saito H, Suzuki K, Mori K: Visualization of neurogenesis in the central nervous system using nestin promoter-GFP transgenic mice. Neuroreport 2000, 11(9):1991-1996.

40. Barcia C, Ros CM, Carrillo MA, Ros F, Gomez A, de Pabios V, Bautista-Hernandez V, Sánchez-Bahillo A, Villalba EF, Herrero MT: Increase of secondary processes of microglial and astroglial cells after MPTPinduced degeneration in substantia nigra pars compacta of non human primates. J Neural Trans Supp/ 2009, 73:253-258.

41. Chen ZJ, Negra M, Levine A, Ughrin Y, Levine JM: Oligodendrocyte precursor cells: reactive cells that inhibit axon growth and regeneration. J Neurocytol 2002, 31(6-7):481-495.

42. Miller RL, James-Kracke M, Sun GY, Sun AY: Oxidative and inflammatory pathways in Parkinson's disease. Neurochem Res 2009, 34(1):55-65. 
43. Bezard E, Dovero S, Imbert C, Boraud T, Gross CE: Spontaneous long-term compensatory dopaminergic sprouting in MPTP treated mice. Synapse 2000, 38:363-368.

44. Mitsumoto $\mathrm{Y}$, Watanabe A, Mori A, Koga N: Spontaneous regeneration of nigrostriatal dopaminergic neurons in MPTP-treated C57BL/6 mice. Biochem Biophys Res Commun 1998, 248:660-663.

45. Smith BA, Goldberg NR, Meshul CK: Effects of treadmill exercise on behavioral recovery and neural changes in the substantia nigra and striatum of the 1-methyl-4-phenyl-1,2,3,6-tetrahydropyridine-lesioned mouse. Brain Res 2011, 1386:70-80

46. Lau YS, Patki G, Das-Panja K, Le WD, Ahmad SO: Neuroprotective effects and mechanisms of exercise in a chronic mouse model of Parkinson's disease with moderate neurodegeneration. Eur J Neurosci 2011, 33(7):1264-1274

47. Bull ND, Bartlett PF: The adult mouse hippocampal progenitor is neurogenic but not a stem cell. J Neurosci 2005, 25(47):10815-10821.

doi:10.1186/1471-2202-13-132

Cite this article as: Klaissle et al:: Physical activity and environmental enrichment regulate the generation of neural precursors in the adult mouse substantia nigra in a dopamine-dependent manner. $B M C$

Neuroscience 2012 13:132

\section{Submit your next manuscript to BioMed Central and take full advantage of:}

- Convenient online submission

- Thorough peer review

- No space constraints or color figure charges

- Immediate publication on acceptance

- Inclusion in PubMed, CAS, Scopus and Google Scholar

- Research which is freely available for redistribution 